The new products and services listed below were selected by the editors based on potential interest to JAOA's readers. Listings are prepared from information supplied by the companies cited or by their agents and are presented for informational value only. Publication in no way constitutes endorsement or warranty by THE JOURNAL OF THE AMERICAN OSTEOPATHIC ASSOCIATION or by the American Osteopathic Association. In contacting the companies, please mention JAOA.

\section{Cholesterol-lowering drug}

Mevacor ${ }^{\circledast}$ is the first of a new class of cholesterol-lowering drugs called "enzyme inhibitors." It works by inhibiting the enzyme HMG-CoA reductase. It is indicated as an adjunct to low-fat, low-cholesterol diet for reducing the elevated total and lowdensity lipoprotein cholesterol levels in patients with primary hypercholesterolemia, who have not responded adequately to diets or nondrug treatments alone. The tablets come in $20 \mathrm{mg}$. dosage strength and are packaged in bottles of 60 or packets of 100 . For more information on Mevacor ${ }^{\circledast}$ tablets, contact Merck Sharp \& Dohme, Division of Merck \& Co., Inc., West Point, Pennsylvania 19486 (215) 661-7485.

\section{Discreet insulin delivery}

Similar in appearance to a fountain pen, the NovoPen contains everything needed for short-acting regular insulin injections. This method of insulin delivery contains a replaceable insulin cartridge (PenFill) of semi-synthetic Novolin R Human Insulin Injection, and a sterile, disposable PenNeedle. NovoPen comes in its own case with room for three PenNeedles and 1 spare insulin cartridge. Depressing the push button once delivers 2 units of insulin. Each cartridge contains 150 units of insulin, approximately a one-week supply. The PenFill cartridge currently in use need not be refrigerated; it can be stored at room temperature for as long as 1 month. For more information on the NovoPen, contact Squibb-Novo, Inc., 120 Alexander Street, Princeton, New Jersey 08540. Outside New Jersey (800) 334-3678 or within New Jersey (800) 367-0249.

\section{Headlamps and mirrors}

A universal connector enables the Halogen 5000 lamp to be interchanged with small or large clear mirrors without removing the headboard. The ball and socket joint provides variation in depth, height, and lateral adjustment. At approximately $40.64 \mathrm{~cm}$. (16 inches) the

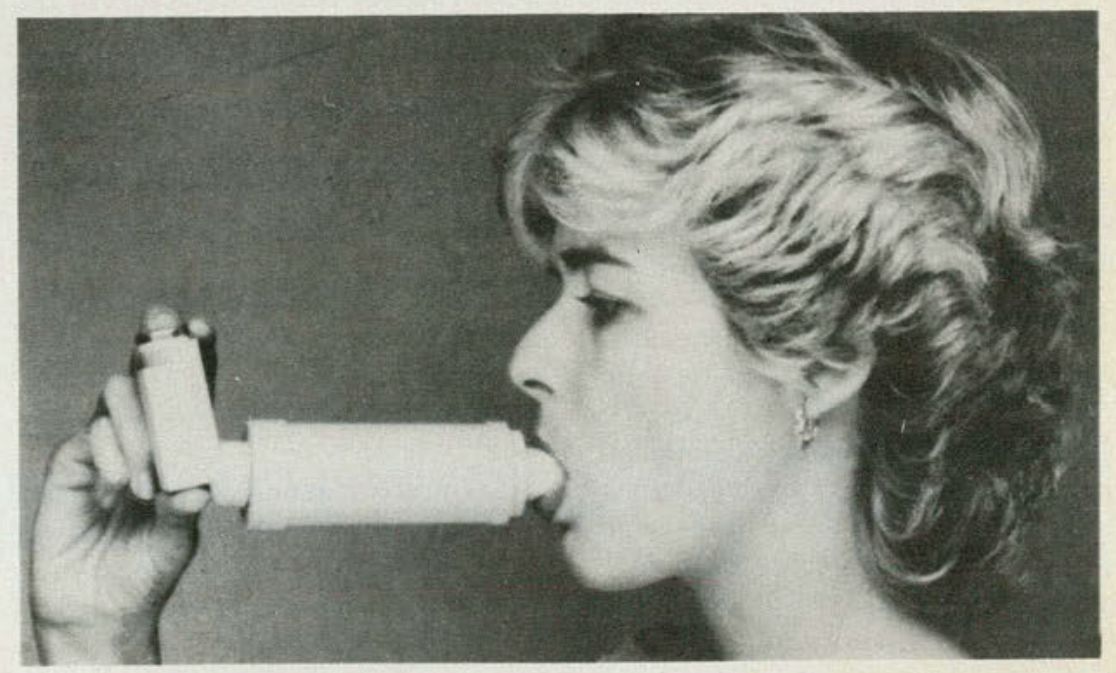

lamp's focusing lens permits adjustment of the iris diameter from 50 $\mathrm{mm}$. ( 2 inches) to $250 \mathrm{~mm}$. (10 inches) without varying light intensity; maximum intensity is 10,000 lux. For more information on the Halogen 5000 , contact LifeMed Technologies, Inc., 8630 Westpark Drive, Houston, Texas 77063 (800) LIFEMED or in Texas (713) 952-0500.

\section{Asthma aerosal inhaler holder}

A plastic tubular holding chamber eliminates the need for hand-breath coordination enabling the asthma patient to inhale the medication slowly. The AeroChamber ${ }^{\star}$ features a one-way valve that allows the user to inhale the spray while not exhaling it back into the holding chamber. Most of the propellant evaporates in the tube. Large droplets are deposited on the chamber's sides; smaller particles are inhaled. For more information on the AeroChamber ${ }^{\circledast}$, contact Forest Laboratories, Inc., 150 East 58th Street, New York, New York 10155-0015 (212) 421-7850. 